\title{
First measurement of ice-bedrock interface of alpine glaciers by cosmic muon radiography
}

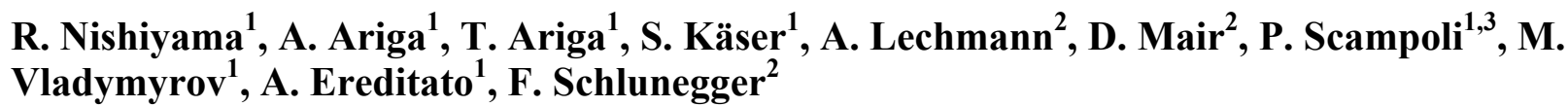

${ }^{1}$ Albert Einstein Center for Fundamental Physics, Laboratory for High Energy Physics, University of Bern, Bern, Switzerland.

${ }^{2}$ Institute for Geological Sciences, University of Bern, Bern, Switzerland.

${ }^{3}$ Department of Physics “E. Pancini”, University of Naples Federico II, Naples, Italy.

Corresponding author: Ryuichi Nishiyama (ryuichi.nishiyama@lhep.unibe.ch)

\section{Key Points:}

- Muon radiography is applied to an alpine glacier for the first time

- The technique reveals the depth profile of the bedrock under the uppermost part of the Aletsch glacier

- The bedrock shape gives clues on the mechanism of the glacial erosion 


\begin{abstract}
The shape of the bedrock underneath Alpine glaciers bears vital information on the erosional mechanism related to the flow of ice. So far, several geophysical exploration methods have been proposed to map the bedrock topography though with limited accuracy. Here, we illustrate the first results from a technology, called cosmic-ray muon radiography, newly applied in glacial geology to investigate the bedrock geometry beneath the Aletsch glacier situated in the Central Swiss Alps. For this purpose we installed new cosmic muon detectors made of emulsion films at three sites along the Jungfrau railway tunnel and measured the shape of the bedrock under the uppermost part of Aletsch glacier (Jungfraufirn). Our results constrain the continuation of the bedrock-ice interface up to a depth of $50 \mathrm{~m}$ below the surface, where the bedrock underneath the glacier strikes NE-SW and dips at $45^{\circ} \pm 5^{\circ}$. This documents the first successful application of this technology to a glaciated environment.
\end{abstract}

\title{
1 Introduction
}

In mountainous landscapes such as the Central Alps of Europe the bedrock topography is one of the most prominent surfaces as it separates the geological substratum - the bedrockfrom the overlying unconsolidated units, which are commonly assigned to the Quaternary [Preusser et al., 2010]. In low-elevated regions this surface has been sculpted by glaciers during past glaciations [e.g. Horberg and Anderson, 1956]. In the highly elevated regions of the European Alps, however, glacial processes are still actively modulating the bedrock topography mainly above the Equilibrium Line Altitude (ELA). Accordingly, the geometry of the bedrock topography sets tight constraints on the erosional mechanisms at work underneath a glacier [e.g. Cook \& Swift, 2012]. This is the major motivation why several efforts have been undertaken towards exploring the bedrock topography surrounding formerly and still actively glaciated areas using drilling [Dürst \& Schlunegger, 2013] and several geophysical techniques, including seismic surveys and multi-beam bathymetry [Duchesne et al., 2010; Dürst et al., 2012], gravity measurements [Adams \& Hinze, 1990; Barnaba et al., 2010], and radio-echo soundings [Fisher et al., 1989; Shean \& Marchant, 2010]. Despite the progress achieved through the application of these geophysical surveys the accuracy of bedrock maps varies greatly because of the assumption on which the reconstruction relies. For instance, bedrock surfaces with steep slopes and/or an overlying medium with a high fluid pressure ratio lower the resolution of seismic and radar surveys and set limits to the penetration depth of the related waves [Murray et al., 2007; Schrott \& Sass, 2008]. In addition, most of previous investigations have either been conducted on landscapes where glaciers have disappeared after the termination of the last glacial epoch ca. 20 '000 years ago, or on active glaciers where the surrounding landscape is flat.

In this paper we introduce a technology referred to as emulsion film muon radiography to investigate the bedrock geometry beneath active glaciers in a steep Alpine environment. This detector technique relies on the high penetration power of muon components in natural cosmic rays, where the attenuation rate of the intensity of muons mainly depends on the density of the crossed material. Accordingly, this method provides a suitable alternative to other approaches because of the large density contrasts between the bedrock and the overlying glacier. In addition, the passive nature of the detecting device, not requiring electric power, computing support or radio data transmission, is an added value to the currently available geophysical tools. We demonstrated the performance of muon radiography through an experiment in the Jungfrau region, Switzerland. We benefit from the railway tunnel of the Jungfraubahn situated in the 
Jungfrau region. This tunnel crosses the bedrock at typically $50 \mathrm{~m}$ depth from the uppermost part of Aletsch glacier (Jungfraufirn). We installed emulsion films at three sites along this tunnel and mapped the shape of the bedrock under the glacier. We then used the patterns of detected muons to map the orientation of the bedrock underneath this glacier, thereby documenting the first successful application of muon radiography in a steep and glaciated environment.

\section{Muon radiography}

Muon radiography is a technology that has been developed to investigate the internal density structures of geological targets. It relies on the high penetration power of the muon particles, a component of the natural cosmic rays [Patrignani et al., 2016]. The absorption rate of the muon flux can be used to derive the density-length, i.e. the density integrated along the muon trajectories. This technique has been applied for non-invasive inspection purposes where the survey targets were volcanoes [Tanaka et al., 2007; Lesparre et al., 2010; Carbone et al., 2014; Ambrosino et al., 2015; Jourde et al., 2016], nuclear reactors [Fujii et al., 2013], seismic faults [Tanaka et al., 2011] and caves [Oláh et al., 2013]. One requirement is that muon detectors must be placed at altitudes lower than survey targets because of downward-going nature of cosmic ray muons. At sites where the interface between a glacier and the bedrock is the survey target, the muon radiography technology bears the potential to return the related densities as a result. Accordingly, because of the anticipated large density contrasts in such an environment, this technology provides information pertinent for mapping the shape of the bedrock at high resolution.

There are several types of particle detectors suitable for muon radiography, such as scintillation trackers [e.g., Lesparre et al., 2010; Anastasio et al., 2013], gaseous chambers [e.g., Cârloganu et al., 2013; Oláh et al., 2013] and emulsion films [e.g., Tanaka et al., 2007; Nishiyama et al., 2016a]. We adopt emulsion films for the observations of glaciers. Emulsion films are special photographic films, which record trajectories of charged particles [Ereditato, 2013; De Lellis et al., 2011]. The microscope analysis of these trajectories then allows to measure the position and direction of incident muons with the unbeatable resolutions. The spatial and angular resolutions are $1 \mu \mathrm{m}$ and a few milli-radians, respectively. Contrary to other types of particle detectors, emulsion films are suitable for exposure in remote and harsh environments because they do not require power supply or any electronic device for operation.

\section{Setting}

The Aletsch glacier, situated in the Central Alps of Switzerland, is the largest glacier in the Central Swiss Alps. It has a length of $23 \mathrm{~km}$, a volume of $15 \mathrm{~km}^{3}$ and covers an area of 81 $\mathrm{km}^{2}$ (Figure 1). The glacier is fed by three tributary glaciers (Ewigschneefeld, Jungfraufirn and Grosser Aletschfirn). The target region of our observation is the uppermost part of Jungfraufirn, which sits on the south-eastern flank of Mt. Jungfrau (4158 m a.s.1.) and Mt. Moench (4107 m a.s.1.). It has a length of $4 \mathrm{~km}$ and a width of about $2 \mathrm{~km}$.

The Aletsch glacier has shortened by about $5 \mathrm{~km}$ during the past 100 years in response to global warming [Hock et al., 1999; Huss et al., 2008]. In the target region a rapid drop of the ice surface in the order of several meters per year has been reported by the local authorities, which is ultimately linked with the shrinkage of the Aletsch glacier. As the Jungfraujoch, which represents the pass between the Mönch and the Jungfrau, hosts infrastructure buildings (train and research stations, communication and tourist facilities) that were constructed on top of the 
bedrock above the Jungfraufirn (Figure 1a), a shrinking of the ice volume and the related drop of the ice surface have large consequences on the mechanical stability of the bedrock underlying these constructions. Accordingly, attention has been paid by local authorities for predicting potential collapse failures of the bedrock, where the vanishing ice decreases the stability of the bedrock. A precise understanding of the shape of the bedrock beneath the glacier would thus help to predict future potential risks for the occurrence of those events.

\section{Experimental design and methods}

The muon detectors were installed at three sites along the Jungfrau railway tunnel facing the Aletsch glacier. Installation took place on 16 February 2016 and removal on 4 April 2016, thereby collecting data during 47 days. The sites (D1-D3) are located $\sim 100 \mathrm{~m}$ apart from each other (Figure 1b) at altitudes of $3381 \mathrm{~m}$ a.s.l. for D1, $3401 \mathrm{~m}$ a.s.l. for D2 and $3414 \mathrm{~m}$ a.s.l. for D3. The individual detector (Figure 2a) consists of a stack of eight layers of emulsion films with 1-mm-thick lead plates between each one (Figure 2b). The emulsion film is made of a $200-\mu \mathrm{m}-$ thick plastic base and a 50- $\mu \mathrm{m}$-thick sensitive gel poured on both sides. The gel production and pouring have been done at Nagoya University, Japan [Nishio et al., 2015] and at the University of Bern, respectively. This design yields to a total effective detection area of $250 \mathrm{~cm}^{2}$ for each site.

After completion of the measurements the films were chemically developed and automatically scanned at the University of Bern by means of optical microscopes. The microscope scanning facility consists of commercially available optics and stages [Arrabito et al., 2006] that are complemented with algorithms for image processing and track recognition that we developed for these purposes [Ariga \& Ariga, 2013]. Tracks that are straightly aligned in consecutive films are identified as muon trajectories, here defined by at least four tracks within the total of eight films. This selection assures a detection efficiency $>97 \%$ and a low contamination of low-energy background particles $(<\sim 1 \mathrm{GeV} / \mathrm{c}$, see Nishiyama et al. 2016b for details). We scanned $13 \%$ of the total detection area $\left(32 \mathrm{~cm}^{2} \times\right.$ eight consecutive layers for each detector site). The number of detected muons were then counted for each bin in a polar coordinate histogram (Figure 3a) and converted into the particle flux $\left(\mathrm{cm}^{-2} \mathrm{~s}^{-1} \mathrm{sr}^{-1}\right.$, Figure 3b) by normalizing with respect to the scanned area $\left(32 \mathrm{~cm}^{2}\right)$, the exposure time $\left(4.12 \times 10^{6} \mathrm{~s}\right)$ and the solid angle.

The comparison of the observed muon flux $\mathrm{F}^{\text {obs }}$ and the simulated one for various densities $\mathrm{F}^{\operatorname{sim}}(\rho)$ returns a density value that gives the best agreement. The simulated flux is calculated by using the muon energy spectrum and the digital elevation models (Supporting Information S1). The agreement between the observed and simulated flux is assessed with a chisquare test:

$$
\chi^{2}(\rho) \equiv \sum_{i}^{\# \text { bins }} \frac{\left|F_{i}^{o b s}-F_{i}^{s i m}(\rho)\right|^{2}}{\sigma_{i}^{2}},
$$

where the error $\sigma_{\mathrm{i}}$ is a combination of the statistical fluctuations and the systematic errors with flux simulation ( $15 \%$, see Supporting Information S1).

Finally, we mapped the shape of the bedrock using all not empty bins of flux data. We determined the fraction of rock $x$ from the average density values $\langle\rho\rangle$ estimated for each bin (Figure 4a). Considering the bulk density of bedrock component $\rho_{\text {rock }}=2.68 \mathrm{~g} / \mathrm{cm}^{3}$ (see next 
section) and that of ice component $\rho_{\text {ice }}=0.85 \mathrm{~g} / \mathrm{cm}^{3}$ [Huss, 2013], $x$ is determined via a relationship:

$$
<\rho>=\rho_{\text {rock }} \cdot x+\rho_{\text {ice }} \cdot(1-x) .
$$

Once $x$ is obtained for each bin the boundary position can be plotted at a distance $\mathrm{L} x$ from the detector position ( $\mathrm{L}$ is the total thickness of overlying material including bedrock and ice). We only considered those muons within a zenith angle between $0^{\circ}$ and $70^{\circ}$ because the systematic uncertainty affecting the flux simulation is larger than the statistical fluctuation for nearly horizontal muons (see Supporting Information S1). The bedrock shape estimated from muon flux analysis was displayed using the ESRI ArcScene software licensed to the Institute of Geological Sciences of the University of Bern.

\section{Results and Discussion}

Figure 3a shows the angular distribution of muon events reconstructed in a $32 \mathrm{~cm}^{2}$ area of the three detectors. Each dot in the plot corresponds to a detected muon. During 47 days of exposure we observed a total of 4655 (D1), 9348 (D2) and 10606 muons (D3) within the viewing range. The intensity of muon events is clearly anti-correlated with the thickness of the obstacles (rock + ice) along the muon trajectories (Figure 3c). For instance, the shadows of muons where the dots are sparsely distributed coincide with the regions where the bedrock thicknesses are greater than $1 \mathrm{~km}$. This indicates that most of the muons in these directions were absorbed in the thick bedrock edifices of the Jungfrau and the Mönch Mts.

Figure $4 \mathrm{~b}$ illustrates the resultant $\chi^{2}(\rho)$ function for 74 bins covering the rock part ( 5 bins from D1, 31 from D2 and 38 from D3, indicated by the black solid lines in Figure 3b). The minimum $\chi^{2}$ value of 41.68 yields the best density value of $2.68 \pm 0.04\left(\mathrm{~g} / \mathrm{cm}^{3}, 1 \sigma\right)$. This estimation is in good agreement with the bulk density independently measured for rock samples taken near the detectors along the Jungfrau railway tunnel and on the surface $\left(2.65-2.74 \mathrm{~g} / \mathrm{cm}^{3}\right.$, Figure $4 b$, see also Supporting Information S2). We thus applied a uniform density $\rho_{\text {rock }}=2.68$ $\mathrm{g} / \mathrm{cm}^{3}$ for the calculation of the bedrock shape. Figure 5a shows the position of the bedrock reconstructed from each bin of muon flux data. For visualization, we rasterized these point data using $2 \mathrm{~m} \times 2 \mathrm{~m}$ grids (Figure $5 \mathrm{~b}$ ). The reconstructed bedrock can be approximated as a plane with a strike angle of $225^{\circ} \mathrm{N}$ and a dip angle of $45^{\circ}$ up to $50 \mathrm{~m}$ depth below the glacier's surface. The cross-sectional view from the middle detector (D2) is represented in Figure 5c. The bedrock shapes reconstructed for two extreme ice densities $\left(0.50\right.$ and $\left.0.90 \mathrm{~g} / \mathrm{cm}^{3}\right)$ are also displayed. Taking into account the uncertainty on the bulk density of ice, the dip angle has a systematic error of $\pm 5^{\circ}$. This uncertainty is mainly related to (i) the selection of the muon energy spectrum model, (ii) unknown density variations of ice, and (iii) seasonal variations of the ice surface. As a first major source of errors, the calculation of muon flux has a systematic uncertainty of $15 \%$. This results in a density estimation error of $\sim 5 \%$. The second source of errors, related to the poorly constrained depth dependence of ice density, is addressed here through the use of two mentioned extreme ice density values, thereby considering these as systematic uncertainties and thus deviations from a mean ice density value of $0.85 \mathrm{~g} / \mathrm{cm}^{3}$ that we applied as default for the calculation of the bedrock-ice interface illustrated in Figure 5c. The implementation of a more realistic depth-dependency of ice densities would significantly reduce the uncertainties of the inferred bedrock orientation. The third factor, i.e. the seasonal variation of the ice surface represented here through a Digital Elevation Model (DEM), is not a problem for the present 
work because the DEM used in the analysis was recently taken and the annual snow accumulation at the research site is merely a few meters.

Most important, our survey shows that the dip and strike angles of the reconstructed bedrock surface agree with those of the hillslope exposed above the glacier. In addition, the orientation of the bedrock is parallel to the glacier's flow direction estimated from the topography of the glacier surface (Figure 1a). These morphometric data indicate that the ice, at least within $50 \mathrm{~m}$ depth below the surface, has passively slid on the pre-existing hillslope. This suggests that the ice has not exerted a strong erosional power along this reach. However, because of the steep dip of the bedrock-ice interface, a further lowering of the ice surface in response to ongoing warming will strongly increase the risk for bedrock failure in the area surrounding the research station (Figure 1a).

\section{Conclusions}

We demonstrated a successful application of muon radiography performed with emulsion film detectors. The results suggest that the uppermost part of Aletsch glacier (Jungfraufirn) is underlain by a bedrock with a steep flank that dips at $45^{\circ} \pm 5^{\circ}$ and strikes at $225^{\circ} \mathrm{N}$. These values have been measured up to a depth of $50 \mathrm{~m}$ below the ice surface. The parallel orientation of the bedrock with respect to the glaciers' flow direction implies that the ice has passively on the bedrock without sculpting it. Muon radiography can be a complementary method for determination of the bedrock topography in a steep glaciated environment if underneath tunnels or suitable detector sites are available.

\section{Acknowledgments}

This project is financially supported by Swiss National Science Foundation as an interdisciplinary research project (159299). We also benefited from the emulsion films R\&D project supported by Swiss National Science Foundation Ambizione grant PZ00P2_154833. We warmly acknowledge M. Nakamura and his colleagues from F-lab, Nagoya University. We would like to express our gratitude to Jungfraubahn for the enormous help with the detector installation. The digital elevation model of the Jungfrau region was provided by Swisstopo. We would like to acknowledge the precious contributions of the technical staff from the LHEP and the Institute for Geological Science of the University of Bern. We would like to thank two anonymous reviewers for useful suggestions that helped us to improve the manuscript. The original data used in the analysis and the details of the methods are available from Supporting Information.

\section{References}

Adams, J. M., and W. J. Hinze (1990), The Gravity-Geologic Technique of Mapping Buried Bedrock Topography, Soc. Explor. Geophys., 3, 99-106, doi:10.1190/1.9781560802785.3.ch7.

Abrecht, J. (1994), Geologic Units of the Aar Massif and Their Pre-Alpine Rock Associations: A Critical Review, Schweizerische Mineralogische Und Petrographische Mitteilungen 74 (1): 5-27. doi:10.5169/seals-56328. 
Allkofer, O. C., G. Bella, W. D. Dau, H. Jokisch, G. Klemke, Y. Oren, R. Uhr, Cosmic ray muon spectra at sea-level up to $10 \mathrm{TeV}$, Nuclear Physics B, 259(1), 1-18, doi:10.1016/05503213(85)90294-9.

Ambrosino, F., A. Anastasio, A. Bross, S. Béné, P. Boivin, L. Bonechi, C. Cârloganu, R. Ciaranfi, L. Cimmino, Ch. Combaret, et al. (2015), Joint measurement of the atmospheric muon flux through the Puy de Dôme volcano with plastic scintillators and Resistive Plate Chambers detectors, J. Geophys. Res. Solid Earth, 120, 7290-7307, doi:10.1002/2015JB011969.

Anastasio, A., F. Ambrosino, D. Basta, L. Bonechi, M. Brianzi, A. Bross, S. Callier, F. Cassese, G. Castellini, R. Ciaranfi, L. Cimmino, R. D'Alessandro, B. De Fazio, C. de La Taille, F. Garufi, G. Iacobucci, M. Martini, V. Masone, C. Mattone, S. Miyamoto, M.C. Montesi, R. Nishiyama, P. Noli, M. Orazi, L. Parascandolo, G. Passeggio, R. Peluso, A. PlaDalmau, L. Raux, R. Rocco, P. Rubinov, G. Saracino, E. Scarlini, G. Scarpato, G. Sekhniaidze, O. Starodubtsev, P. Strolin, A. Taketa, H.K.M. Tanaka, M. Tanaka, T. Uchida (2013) The MU-RAY experiment. An application of SiPM technology to the understanding of volcanic phenomena, Nucl. Instrum. Methods Phys. Res., Sect. A, 718, 134-137, doi:10.1016/j.nima.2012.08.065.

Ariga, A., and T. Ariga (2014) Fast $4 \pi$ track reconstruction in nuclear emulsion detectors based on GPU technology, J. Instrum., 9, P04002, doi:10.1088/1748-0221/9/04/P04002.

Arrabito, L., E. Barbuto, C. Bozza, S. Buontempo, L. Consiglio, D. Coppola, M. Cozzi, J. Damet, N. D’Ambrosio, G. De Lellis, M. De Serio, F. Di Capua, D. Di Ferdinando, D. Di Marco, L.S. Esposito, G. Giacomelli, G. Grella, M. Hauger, F. Juget, I. Kreslo, M. Giorgini, M. Ieva, I. Laktineh, K. Manai, G. Mandrioli, A. Marotta, S. Manzoor, P. Migliozzi, P. Monacelli, M.T. Muciaccia, A. Pastore, L. Patrizii, C. Pistillo, M. Pozzato, P. Royole-Degieux, G. Romano, G. Rosa, N. Savvinov, A. Schembri, L. Scotto Lavina, S. Simone, M. Sioli, C. Sirignano, G. Sirri, G. Sorrentino, P. Strolin, V. Tioukov, T. Waelchli (2006) Hardware performance of a scanning system for high speed analysis of nuclear emulsions, Nucl. Instrum. Methods Phys. Res., Sect. A, 568(2), 578-587, doi:10.1016/j.nima.2006.06.072.

ASTM C914-09 (2015), Standard Test Method for Bulk Density and Volume of Solid Refractories by Wax Immersion, ASTM International, West Conshohocken, PA, 2015. doi:10.1520/C0914-09R15; www.astm.org

Barnaba, C., L. Marello, A. Vuan, F. Palmieri, M. Romanelli, E. Priolo, and C. Braitenberg (2010) The buried shape of an alpine valley from gravity surveys, seismic and ambient noise analysis. Geophys. J. Int., 180, 715-733. doi:10.1111/j.1365-246X.2009.04428.X

Blake, G.R. and Hartge, K.H., 1986. Bulk Density. in: Klute, A., Ed., Methods of Soil Analysis, Part 1, 2nd Edition, Agron. Monogr. 9, American Society of Agronomy and Soil Science Society of America, Madison, 363-375.

Carbone, D., D. Gibert, J. Marteau, M. Diament, L. Zuccarello and E. Galichet (2014) An experiment of muon radiography at Mt Etna (Italy). Geophys. J. Int., 196, 633-643, doi:10.1093/gji/ggt403

Cârloganu, C., V. Niess, S. Béné, E. Busato, P. Dupieux, F. Fehr, P. Gay, D. Miallier, B. Vulpescu, P. Boivin, C. Combaret, P. Labazuy, I. Laktineh, J. F. Lénat, L. Mirabito, and 
A. Portal (2013) Towards a muon radiography of the Puy de Dôme, Geosci. Instrum. Method. Data Syst., 2, 55-60, doi:10.5194/gi-2-55-2013.

Cook, S. J., and D. A. Swift (2012), Subglacial basins: Their origin and importance in glacial systems and landscapes, Earth Sci. Rev., 115, 332-372, doi:10.1016/j.earscirev.2012.09.009.

De Lellis, G., Ereditato, A., and Niwa, K. Nuclear Emulsions, C.W. Fabjan and H. Schopper eds., Springer Materials. Landolt-Bönstein Database, Springer-Verlag, Heidelberg Germany (2011) doi=10.1007/978-3-642-03606-4_9

Duchesne, M. J., Pinet, N., Bédard, K., St-Onge, G., Lajeunesse, P., Campbell, D. C. and Bolduc, A. (2010), Role of the bedrock topography in the Quaternary filling of a giant estuarine basin: the Lower St. Lawrence Estuary, Eastern Canada. Basin Research, 22, 933-951, doi:10.1111/j.1365-2117.2009.00457.x

Dürst Stucki M, F. Schlunegger, F. Christener, G. Otto J-C. (2012), Deepening of inner gorges through subglacial meltwalter - an example from the UNESCO Entlebuch area, Switzerland, Geomorphology, 139-140: 506-517, doi:10.1016/j.geomorph.2011.11.016.

Dürst Stucki M, F. Schlunegger, (2013), Identification of erosional mechanisms during past glaciations based on a bedrock surface model of the central European Alps, Earth Planet. Sci. Lett., 384: 57-70, doi:10.1016/ j.eps1.2013.10.009.

Ereditato, A. (2013), The Study of Neutrino Oscillations with Emulsion Detectors, Adv. High Energy Phys., 382172, doi: 10.1155/2013/382172.

Fisher, E., G. A. McMechan, M. R. Gorman, A. P. R. Cooper, C. L. V. Aiken, M. E. Ander, and M. A. Zumberge (1989) Determination of bedrock topography beneath the Greenland ice sheet by three-dimensional imaging of radar sounding data, J. Geophys. Res., 94(B3), 2874-2882, doi:10.1029/JB094iB03p02874.

Fujii, H., K. Hara, S. Hashimoto, F. Ito, H. Kakuno, S. H. Kim, M. Kochiyama, K. Nagamine, A. Suzuki, Y. Takeda, Y. Takahashi, F. Takasaki, and S. Yamashita (2013), Performance of a remotely located muon radiography system to identify the inner structure of a nuclear plant, Prog. Theor. Exp. Phys., 073C01, doi:10.1093/ptep/ptt046.

Groom, D. E., N. V. Mokhov, and S. I. Striganov (2001) Muon Stopping Power and Range Tables $10 \mathrm{MeV}$ - $100 \mathrm{TeV}$, Atomic Data and Nuclear Data Tables, 78(2), 183-356, doi:10.1006/adnd.2001.0861.

Haino, S., T. Sanuki, K. Abe, K. Anraku, Y. Asaoka, H. Fuke, M. Imori, A. Itasaki, T. Maeno, Y. Makida, S. Matsuda, N. Matsui, H. Matsumoto, J.W. Mitchell, A.A. Moiseev, J. Nishimura, M. Nozaki, S. Orito, J.F. Ormes, M. Sasaki, E.S. Seo, Y. Shikaze, R.E. Streitmatter, J. Suzuki, Y. Takasugi, K. Tanaka, K. Tanizaki, T. Yamagami, A. Yamamoto, Y. Yamamoto, K. Yamato, T. Yoshida, and K. Yoshimura, Measurements of primary and atmospheric cosmic-ray spectra with the BESS-TeV spectrometer, Phys. Lett. B, 594(1-2), 35-46, doi:10.1016/j.physletb.2004.05.019.

Hebbeker, T., and C. Timmermans (2002) A compilation of high energy atmospheric muon data at sea level, Astroparticle Physics, 18(1), 107-127, doi:10.1016/S0927-6505(01)00180-3. 
Hock, R., A. Iken, and A. Wangler (1999) Tracer experiments and borehole observations in the overdeepening of Aletschgletscher, Switzerland, Annals of Glaciology, 28(1), 253-260.

Huss, M., A. Bauder, M. Funk, and R. Hock (2008) Determination of the seasonal mass balance of four Alpine glaciers since 1865, J. Geophys. Res., 113, F01015, doi:10.1029/2007JF000803.

Huss, M. (2013) Density assumptions for converting geodetic glacier volume change to mass change, The Cryosphere, 7, 877-887, doi:10.5194/tc-7-877-2013.

Jourde, K., D. Gibert, J. Marteau, J. de Bremond d'Ars, J. Komorowski (2016) Muon dynamic radiography of density changes induced by hydrothermal activity at the La Soufrière of Guadeloupe volcano, Scientific Reports, 6, 33406, doi:10.1038/srep33406.

Kremer, J., M. Boezio, M. L. Ambriola, G. Barbiellini, S. Bartalucci, R. Bellotti, D. Bergström et al. (1999) Measurements of ground-level muons at two geomagnetic locations, Phys. Rev. Lett., 83, 4241-4244, doi:10.1103/PhysRevLett.83.4241.

Lesparre, N., D. Gibert, J. Marteau, Y. Déclais, D. Carbone, and E. Galichet (2010) Geophysical muon imaging: feasibility and limits. Geophys. J. Int., 183, 1348-1361, doi:10.1111/j.1365-246X.2010.04790.x.

Murray, T., A. Booth, and D. M. Rippin (2007) Water-content of glacier-ice: Limitations on estimates from velocity analysis of surface ground-penetrating radar surveys, J. Environ. Eng. Geophys., 12(1), 87-99.

Nishio, A., K. Morishima, K. Kuwabara, and M. Nakamura (2015) Development of nuclear emulsion detector for muon radiography, Physics Procedia, 80, 74-77, doi:10.1016/j.phpro.2015.11.084

Nishiyama, R., S. Miyamoto, S. Okubo, H. Oshima, and T. Maekawa (2016a) 3D Density Modeling with Gravity and Muon-Radiographic Observations in Showa-Shinzan Lava Dome, Usu, Japan, Pure Appl. Geophys., in press, doi:10.1007/s00024-016-1430-9.

Nishiyama, R., A. Taketa, S. Miyamoto, and K. Kasahara (2016b) Monte Carlo simulation for background study of geophysical inspection with cosmic-ray muons, Geophys. J. Int., 206, 1039-1050, doi:10.1093/gji/ggw191.

Oláh, L., G. G. Barnaföldi, G. Hamar, H. G. Melegh, G. Surányi, and D. Varga (2013) Cosmic Muon Detection for Geophysical Applications, Advances in High Energy Physics, 2013, 560192, doi:10.1155/2013/560192.

Patrignani, C. et al. (Particle Data Group) (2016) The Review of Particle Physics, Chin. Phys. C, 40, 100001.

Reyna, D. (2006) A Simple Parameterization of the Cosmic-Ray Muon Momentum Spectra at the Surface as a Function of Zenith Angle, arXiv:hep-ph/0604145.

Rietveld, H. M. (1969) A Profile Refinement Method for Nuclear and Magnetic Structures. Journal of Applied Crystallography 2 (2), International Union of Crystallography: 65-71. doi:10.1107/S0021889869006558. 
Schaltegger, U. (1993), The Evolution of the Polymetamorphic Basement in the Central Alps Unravelled by Precise U-Pb Zircon Dating, Contributions to Mineralogy and Petrology 113 (4): 466-78. doi:10.1007/BF00698316.

Schön, J. (2015) Physical Properties of Rocks: Fundamentals and Principles of Petrophysics, in Cubitt, J. (Ed.) Developments in Petroleum Science 65, 2nd Edition, Elsevier.

Schrott, L., and O. Sass (2008) Application of field geophysics in geomorphology: Advances and limitations exemplified by case studies, Geomorphology, 93(1-2), 55-73, doi:10.1016/j.geomorph.2006.12.024.

Shean, D. E., and D. R. Marchant (2010) Seismic and GPR surveys of Mullins Glacier, McMurdo Dry Valleys, Antarctica: ice thickness, internal structure and implications for surface ridge formation, Journal of Glaciology, 56(195), 48-64.

Tanaka, H. K. M., T. Nakano, S. Takahashi, J. Yoshida, M. Takeo, J. Oikawa, T. Ohminato, Y. Aoki, E. Koyama, H. Tsuji, and K. Niwa (2007) High resolution imaging in the inhomogeneous crust with cosmic-ray muon radiography: The density structure below the volcanic crater floor of Mt. Asama, Japan, Earth Planet. Sci. Lett., 263(1-2), 104-113, doi: 10.1016/j.eps1.2007.09.001.

Tanaka, H. K. M., H. Miyajima, T. Kusagaya, A. Taketa, T. Uchida, and M. Tanaka (2011) Cosmic muon imaging of hidden seismic fault zones: Rainwater permeation into the mechanical fractured zones in Itoigawa-Shizuoka Tectonic Line, Japan, Earth Planet. Sci. Lett., 306(3-4), 156-162, doi: 10.1016/j.epsl.2011.03.036. 

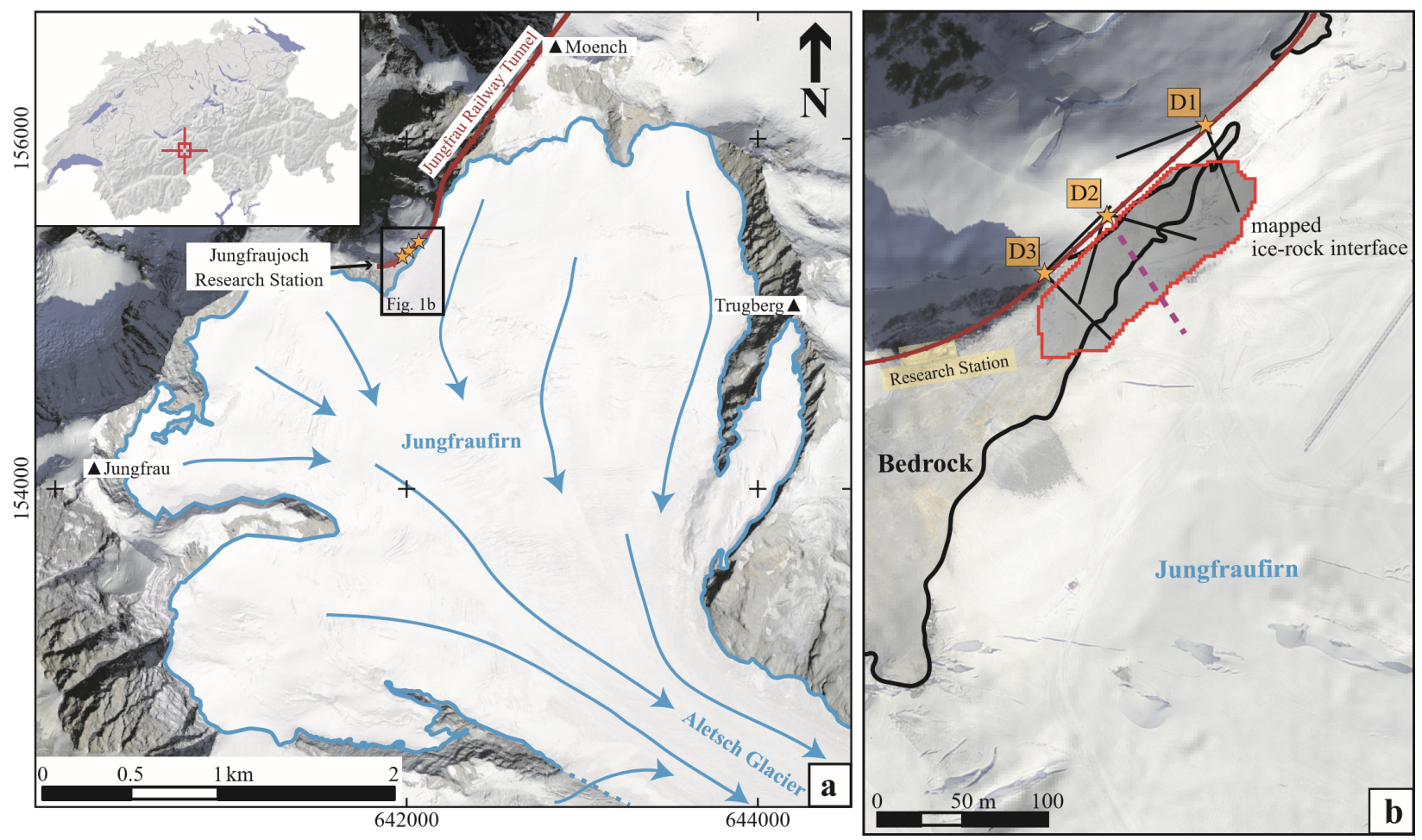

Figure 1. (a) The uppermost part of Aletsch glacier (Jungfraufirn). The blue arrows indicate the direction of glacier flow. (b) View of the survey region. The detectors were installed along the Jungfrau railway (stars D1, D2 and D3). The solid black lines from the detector indicate the view range of each detector. Basemap: SWISSIMAGE (digital color orthophotomosaic, $0.25 \mathrm{~m}$ ground pixel size) draped with a semi-transparent hillshade based on SwissAlti3D, reproduced by permission of swisstopo (BA17061). 
(a)

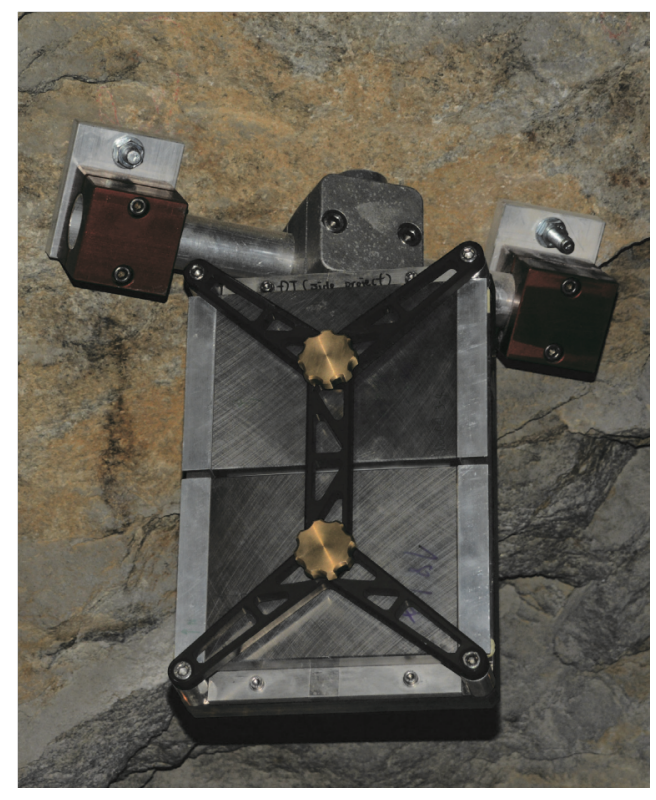

(b)

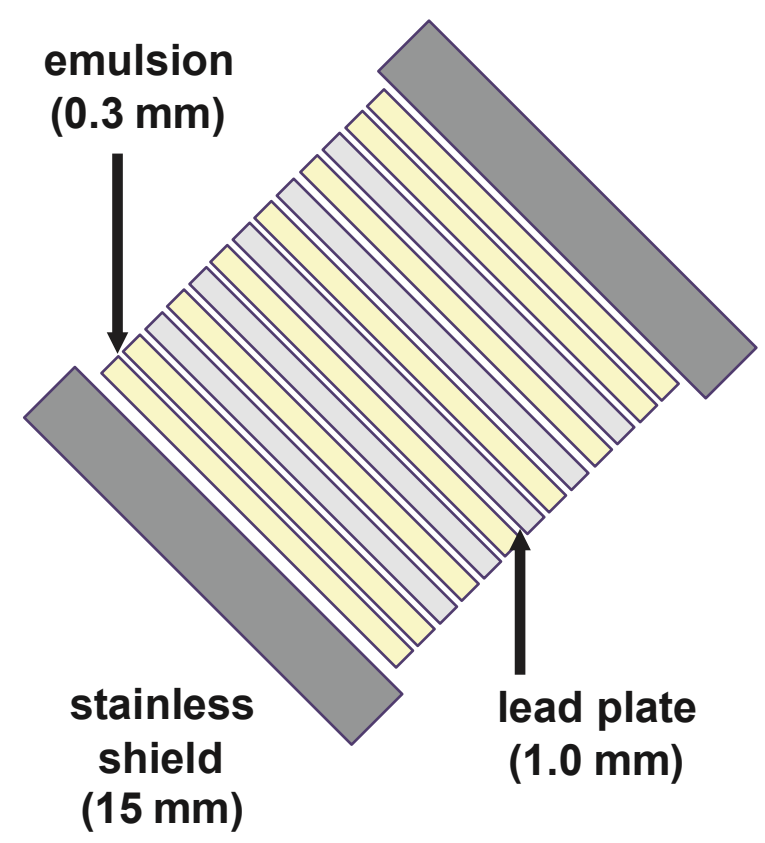

Figure 2. (a) The detector frame is fixed on the wall of the Jungfrau railway tunnel, inclined $45^{\circ}$ with respect to the zenith. (b) The detector consists of eight emulsion films interleaved with 1$\mathrm{mm}$-thick lead plates. It is covered by $\sim 15$-mm-thick stainless plates to shield environmental radioactive particles. 

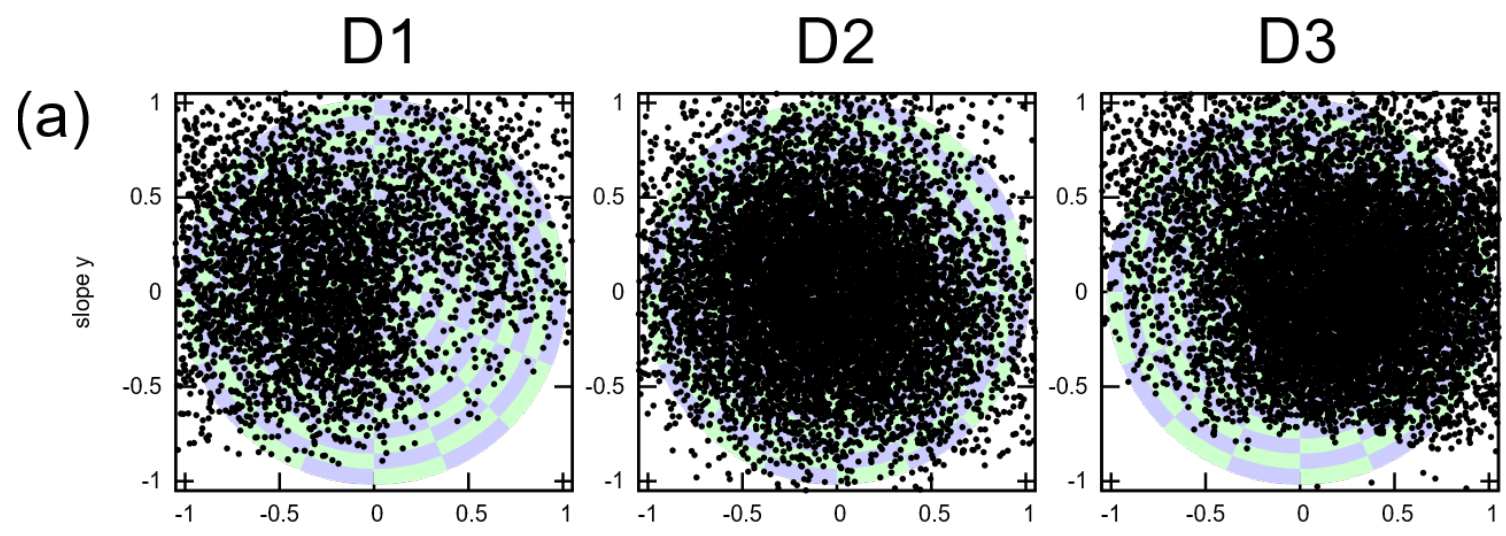

(b)
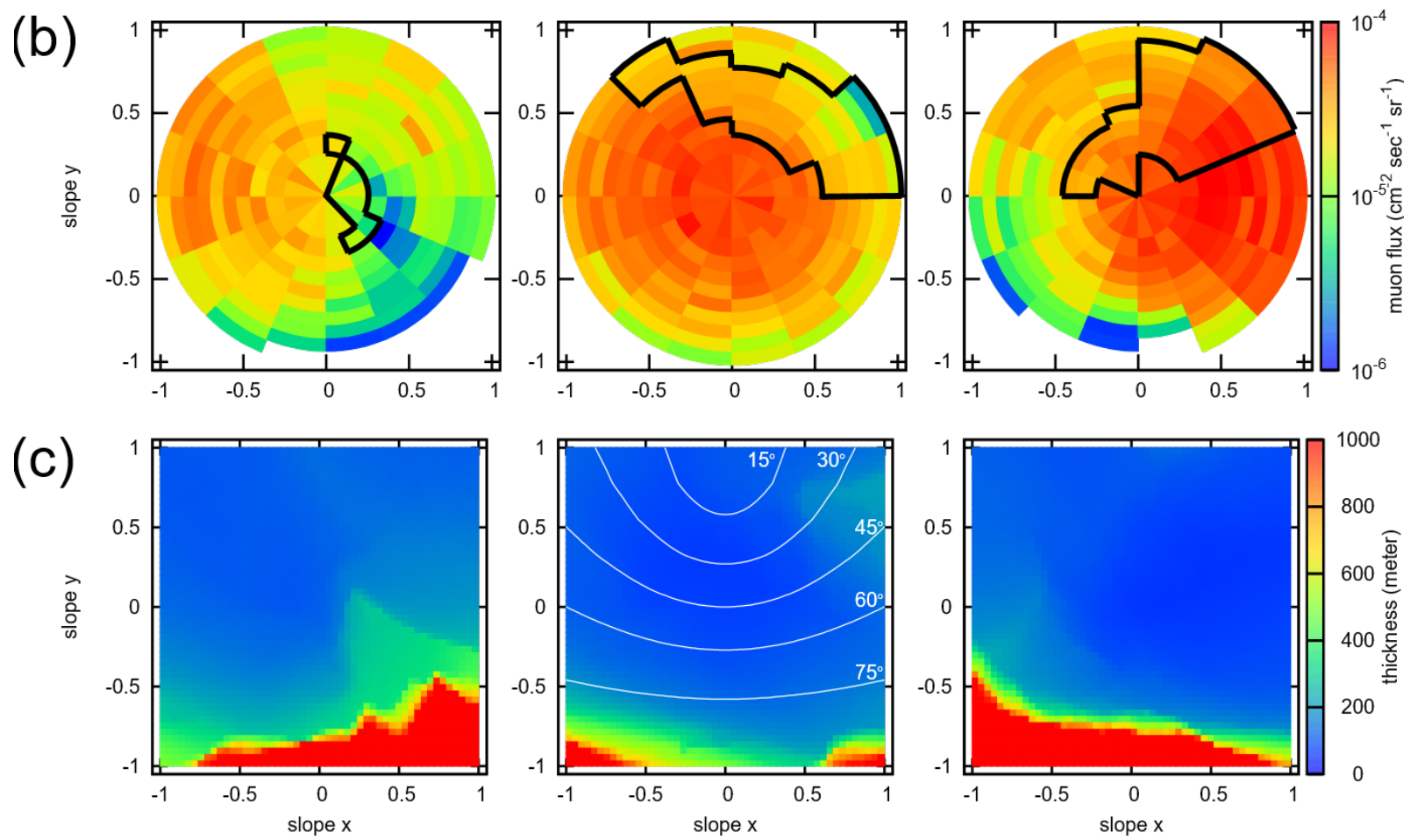

Figure 3. (a) Angular distribution of muons detected in 47 days at D1 (left), D2 (middle) and D3 (right). Each dot corresponds to a single muon event. (b) Muon flux converted for each polar bin by normalizing the number of muon events with respect to the detector size, solid angle and exposure time. The regions enclosed by the black solid lines are not covered with ice and used for estimation of bedrock density. (c) Obstacle thicknesses (rock + ice), traversed by muons before reaching the detectors. The muon intensity is clearly anti-correlated with the thickness. The white contour curves in the middle plot indicate the zenith angle of incoming muons. 
(a)

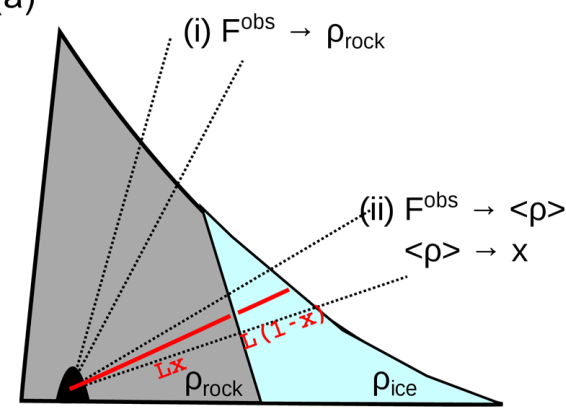

(b)

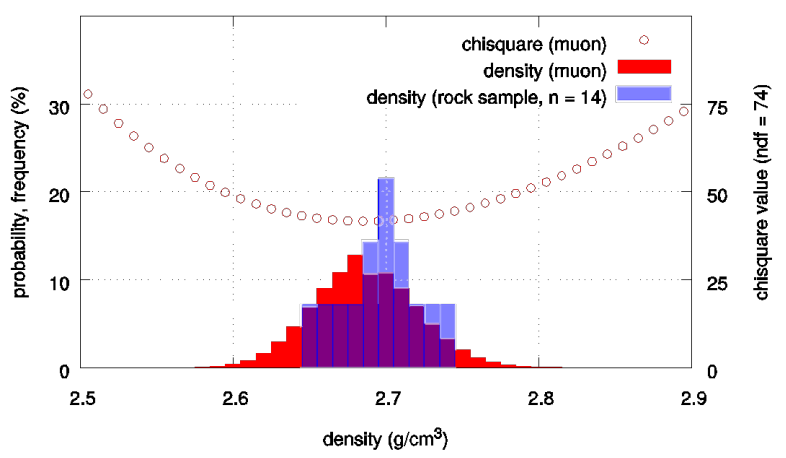

Figure 4. (a) Schematic illustration of (i) bedrock density analysis and (ii) bedrock shape analysis. (b) The $\chi^{2}$ statistics test is performed to determine the rock density. A total of 74 bins covering the hillslope are used for the test, which are indicated by the black solid lines in Figure $3 \mathrm{~b}$. The minimum value of the chi-square is 41.68 (open red circles), giving the best bulk density of $2.68 \pm 0.04\left(\mathrm{~g} / \mathrm{cm}^{3}, 1 \sigma\right.$, red boxes). It agrees with the bulk density measured for rock samples taken near the detectors along the Jungfrau railway tunnel (blue boxes). 
(a)

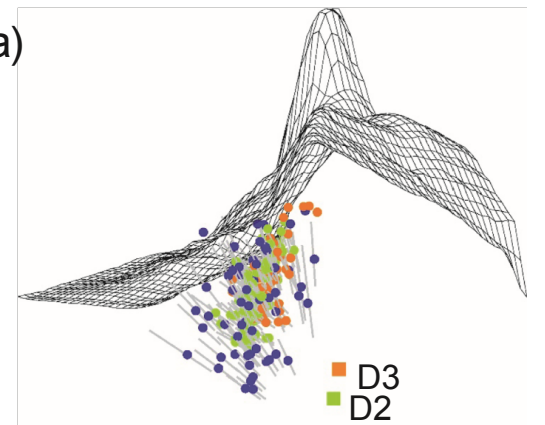

(c)

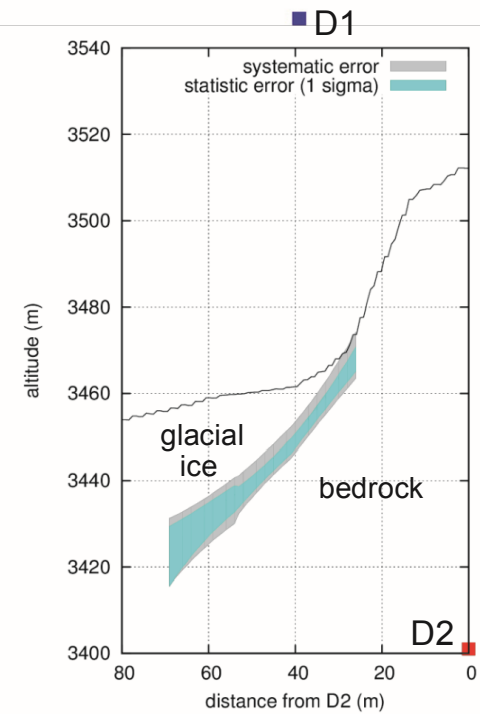

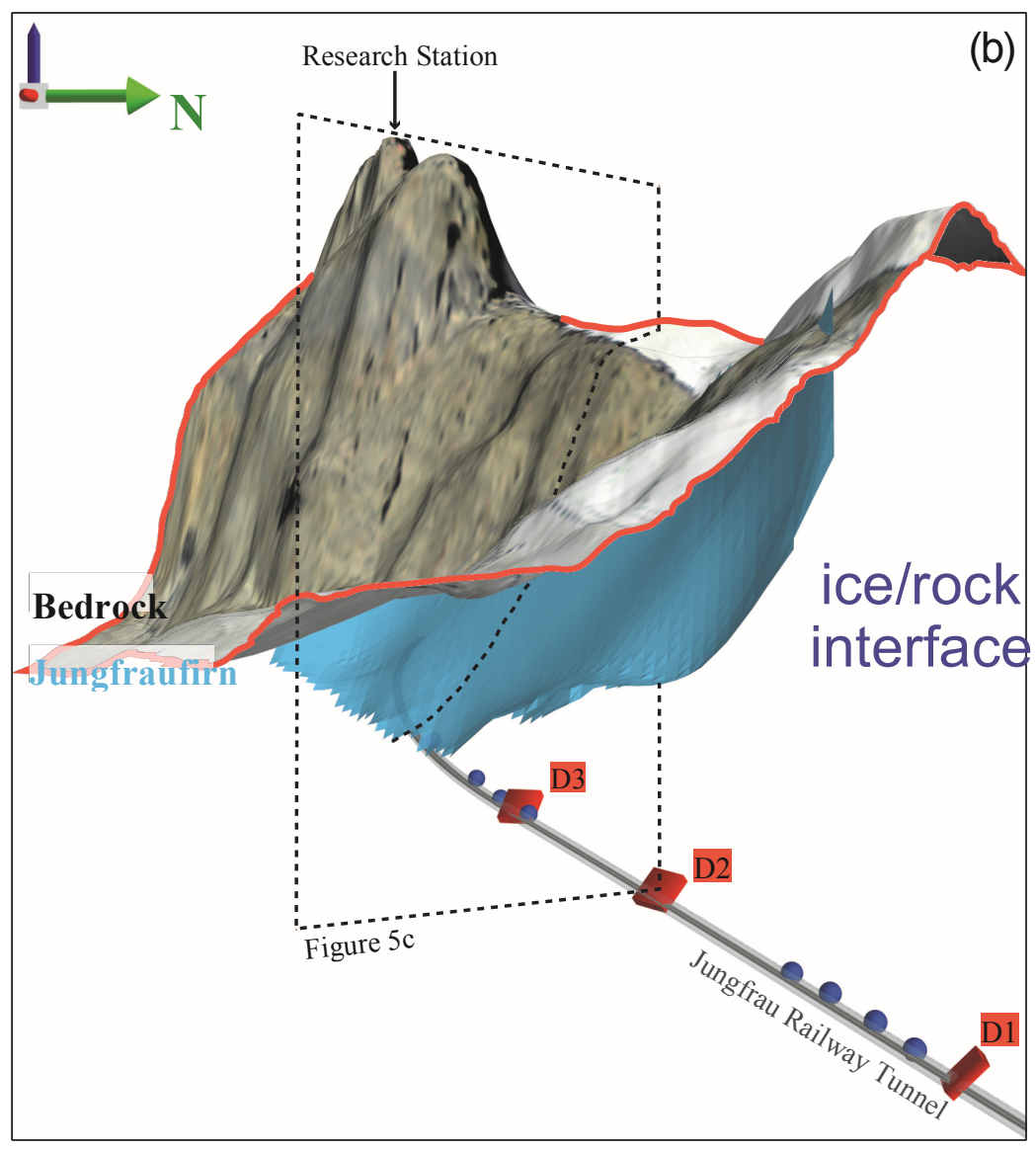

Figure 5. (a) The three-dimensional reconstructed bedrock points under the surface, determined from muon flux attenuation analysis. (b) The point data are rasterized with $2 \mathrm{~m} \times 2 \mathrm{~m}$ grids into the bedrock surface. The locations of rock sampling are also indicated with blue points along the railway tunnel. Basemap: SWISSIMAGE (digital color orthophotomosaic, $0.25 \mathrm{~m}$ ground pixel size) reproduced by permission of swisstopo (BA17061). (c) The cross-sectional view from the middle detector site (D2) along the steepest direction of the bedrock. The blue and grey bands are the $68 \%$ confidence level due to statistical fluctuations and the systematic uncertainty due ice density ambiguity. 